\title{
BMJ Open Quantity and quality of conflict of interest policies at German medical schools: a cross-sectional study and survey
}

Peter Grabitz (D , ${ }^{1,2}$ Zoe Friedmann, ${ }^{1}$ Sophie Gepp, ${ }^{1}$ Leonard Hess, ${ }^{1}$ Lisa Specht, ${ }^{1}$ Maja Struck, ${ }^{1}$ Sophie Kira Tragert, ${ }^{1}$ Tobias Walther, ${ }^{1}$ David Klemperer ${ }^{3}$

To cite: Grabitz P, Friedmann Z, Gepp S, et al. Quantity and quality of conflict of interest policies at German medical schools: a cross-sectional study and survey. BMJ Open 2020;10:e039782. doi:10.1136/ bmjopen-2020-039782

- Prepublication history for this paper is available online. To view these files, please visit the journal online (http://dx.doi. org/10.1136/bmjopen-2020039782).

Received 25 April 2020

Revised 23 July 2020

Accepted 17 August 2020
Check for updates

(C) Author(s) (or their employer(s)) 2020. Re-use permitted under CC BY-NC. No commercial re-use. See rights and permissions. Published by BMJ.

${ }^{1}$ Universities Allied for Essential Medicines Europe e.V, Berlin,

Germany

${ }^{2}$ QUEST Center for Transforming Biomedical Research, Berlin Institute of Health (BIH),Charité - Universitätsmedizin Berlin,

Berlin, Germany

${ }^{3}$ Faculty of Social and Health

Sciences, Regensburg

University of Applied Sciences, Regensburg, Germany

Correspondence to

Peter Grabitz;

peter.grabitz@charite.de

\section{ABSTRACT}

Objectives To assess the quantity and evaluate the quality of policies and curricula focusing on conflicts of interests (COI) at medical schools across Germany. Design Cross-sectional study, survey of medical schools, standardised web search.

Setting Medical schools, Germany.

Participants 38 German medical schools.

Interventions We collected relevant $\mathrm{COI}$ policies, including teaching activities, by conducting a search of the websites of all 38 German medical schools using standardised keywords for COI policies and teaching. Further, we surveyed all medical schools' dean's offices. Finally, we adapted a scoring system for results we obtained with 13 categories based on prior similar studies. Main outcomes and measures Presence or absence of COl-related policies, including teaching activities at medical school. The secondary outcome was the achieved score on a scale from 0 to 26 , with high scores representing restrictive policies and sufficient teaching activities.

Results We identified relevant policies for one medical school via the web search. The response rate of the deans' survey was 16 of $38(42.1 \%)$. In total, we identified COI-related policies for 2 of 38 (5.3\%) German medical schools, yet no policy was sufficient to address all COIrelated categories that were assessed in this study. The maximum score achieved was 12 of 26.36 (94.7\%) schools scored 0 . No medical school reported curricular teaching on $\mathrm{COI}$.

Conclusions Our results indicate a low level of action by medical schools to protect students from undue commercial influence. No participating dean was aware of any curriculum or instruction on $\mathrm{COI}$ at the respective school and only two schools had policies in place. The German Medical Students Association and international counterparts have called for a stronger focus on $\mathrm{COI}$ in the classroom. We conclude that for German medical schools, there is still a long way to go.

\section{INTRODUCTION}

Contacts between the pharmaceutical or medical device industry and healthcare professionals have long been a point of discussion, as they may lead to conflicts of
Strengths and limitations of this study

- This study is the first standardised qualitative analysis of medical school conflict of interest (COI) policies in Germany.

- The cross-sectional study comprises structured web searches and surveys of deans' offices.

- The study design is based on previous studies in other countries and therefore allows for international comparison.

- Despite combining multiple approaches of data collection, teaching activities and policies may have been missed.

- Since this study focused on COI policies that apply to the specific setting of medical schools, other state or university-wide policies were not included.

interest (COI). According to the widely accepted definition from the Institute of Medicine, COI are circumstances that create a risk that professional judgements or actions regarding a primary interest will be unduly influenced by a secondary interest. ${ }^{1}$ In healthcare COI may exist between the physician's commitment to patient care and industry's interest in selling their products. There is mounting evidence indicating an adverse effect of pharmaceutical promotion on physicians' prescribing behaviour. ${ }^{2}$ Patients may suffer from the consequences directly due to exposure to unnecessary risks as well as indirectly through a higher financial burden for healthcare systems. ${ }^{2}$ Simultaneously, universities and medical schools, in particular, are increasingly expected to conduct translational research from 'bench to bedside'-a paradigm that includes market commercialisation and requires industry collaborations which makes contact with the private sector inevitable. Therefore, COI present challenges towards medical professionalism. ${ }^{3}$ 
In order to protect independent patient care, professional handling of COI by physicians is essential. It has been argued, that physicians' attitudes towards the pharmaceutical industry and their inclination to be influenced by marketing efforts manifest early during their professional training. ${ }^{3}$ A large body of evidence exists showing that medical students themselves are in contact with industrial companies on a regular basis. ${ }^{3-11}$ Contacts increase in the course of studies, with more interactions during the clinical part of their studies. ${ }^{4213}$ A study by Lieb and $\mathrm{Koch}^{7}$ at eight German medical schools revealed that only $12 \%$ of surveyed students had never received a gift or attended a sponsored event. The authors also report that $60 \%$ of these students had a promotional gift handed on to them by a physician they worked with, who received the gift by a company beforehand. ${ }^{7}$ Professors and other physicians act as role models students base their attitudes and actions on-not only regarding their clinical work, but also regarding interactions with industry and COI. The actions of those role models constitute a 'hidden curriculum' and conceptualise what is perceived to be normal. ${ }^{14}$ The extent to which teaching faculty in Germany has financial ties to industry actors remains largely unclear. Despite frequent debates, there is currently no German equivalent to the Physician Payments Sunshine Act in USA, where information on payments from industry to physicians is collected, categorised and made publicly available by law. ${ }^{15}$ Data reported by the German nonprofit investigative journalism newsroom CORRECTIV based on voluntary disclosures indicate that physicians, pharmacists and other healthcare professionals together with their respective institutions received a minimum of 562 million euro in 2016 alone. ${ }^{16}$ How many of these providers had teaching responsibilities at medical schools is largely unknown. Such relationships may affect academic and publishing interests, the content faculty chooses to disseminate to medical students and their general professional medical opinions. ${ }^{1718}$ Overall, COI of teaching staff are not commonly disclosed to medical students in Germany.

Previous studies report that $65 \%$ of surveyed medical students in Germany felt inadequately prepared for interactions with the pharmaceutical industry. ${ }^{19} 90 \%$ of those students in Germany reported that dealing with industrial marketing practices had never been addressed during their lectures. ${ }^{19}$ In another survey, $14.4 \%$ of the participating German medical students noted that they attended a lecture or courses dealing with COI; of those classes, however, $90 \%$ were optional. ${ }^{20}$ Altogether, it remains unclear to what extent German medical schools include COI topics in their curricula. Aside from teaching about industry practices of marketing and promotion, restrictive COI policies at the medical school level have been suggested to increase students' awareness of the consequences of inappropriate marketing practices in the learning environment. ${ }^{21}$ Some studies indicate that COI policies at medical schools have a significant impact on prescribing practices by inoculating physicians against persuasive aspects of pharmaceutical promotion. ${ }^{22-24}$ In Germany, Lieb and Koch found that in 2013 only two out of 36 medical schools reported having a COI policy. ${ }^{20}$ However, none of these schools reporting a policy (TU Dresden and RWTH Aachen) supplied the policies themselves and hence, the content and strength of the policies remain unclear. The objective of this study was to determine whether medical schools in Germany have institutional COI policies in place and to assess the strength of the policies obtained by means of 13 predefined criteria including the existence of teaching activities.

\section{METHODS}

Our methodology built on criteria used in earlier studies on COI policies such as the American Medical Students Association (AMSA) scorecard, ${ }^{25}$ the Canadian scorecard by Shnier $e t a l,{ }^{26}$ and the French COI ranking by Scheffer $e t$ $a l .^{27} \mathrm{~A}$ list of the 38 German medical schools was obtained from the website of the German Medical Faculty Association (Medizinischer Fakultätentag).$^{28}$ After the formal exchange with a member of the German Ethics Council about the nature of this study, which only involves policies at an institutional level rather than patient data or other personal information, it was deemed unnecessary to ask for formal approval from an ethics committee.

\section{Patient and public involvement}

Neither patients nor public were involved in conceptualising or conducting this study.

\section{Web-based search}

Two researchers (LS, MS) independently searched the websites of the respective medical schools (or if nonexistent, the websites of the respective universities) using the sites' integrated search engines in June 2018 to identify policies related to COI, documents interpreting policies or material published regarding COI in the curriculum. Addresses of the websites searched are listed in online supplemental file 1 . Search terms included 'Interessenkonflikt' / 'Interessenskonflikt' (conflict of interest), 'Industrie' (industry), and 'interne Regulierung' (internal regulation) based on previous publications. ${ }^{27}$ If a policy was in place, it was recorded together with the latest date of review. Only policies that specified their validity for medical schools were considered relevant for this study. Therefore, policies applying to an entire university or only to a university hospital were excluded. Disagreement about the inclusion of the recorded sources was discussed with all authors. Those sources included were later assessed via the methodology previously determined through the scoring criteria in our codebook (as described in the Results section, see online supplemental file 2).

\section{Contacting medical schools}

In May 2018, we contacted each office of the dean of medicine to inform them about the study through a written 
letter (see online supplemental files 3 and 4). The letter gave background information about the study's purpose and outlined the criteria for which we needed documentation. We asked the medical school to send any form of policy (or parts of a policy) relating to the management of COI, as well as information on enforcement of the policy. Furthermore, the letter included the request to provide information on curriculum contents addressing the consequences and management of COI. We did a maximum of three follow-ups for non-responders. We first sent an email in June 2018 reiterating the content of the letter previously sent. We then followed up via email in July 2018 and enclosed two letters of support, one from David Klemperer and one from Barbara Mintzes, co-author of the study which analysed COI policies at Canadian medical schools and editor of a teaching manual on pharma promotion. ${ }^{29}$ In August 2018, we followed up by sending the results of the web-based search. Representatives of the dean's offices were given the opportunity to confirm, correct or comment on our web-based findings. In addition to searching the websites and contacting the offices of the deans of medical schools, we sought information via personal contacts and experts in the field. Data cut-off was October 2018. We excluded policies from affiliated teaching hospitals because they are not under the authority of the dean of the medical school. Further, we excluded any policies or parts of policies that did not specifically apply to a medical school.

\section{Scoring system}

We adapted a scoring system based on criteria used in earlier studies by Scheffer $e t a l^{27}$ and Shnier $e t a l^{26}$ in the French and Canadian context, respectively, as well as the AMSA Scorecard. ${ }^{25}$ The following categories were addressed:

1. Gifts from industry.

2. Meals from industry.

3. Consulting relationships.

4. Industry-funded promotional speaking.

5. Educational activities, such as Continuing Medical Education (CME) lectures.

6. Participation in industry-funded promotional events.

7. Honoraria and scholarships from industry.

8. Ghostwriting and honorary authorships.

9. Industry Sales Representatives.

10. Disclosure of COI.

11. Medical school curriculum on COI.

12. Extension of policies.

13. Enforcement of policies.

Of note for category 11 'Medical school curriculum on COI': German medical schools are not likely to implement policies that describe COI as an obligatory component of the curriculum. We accounted for this by (a) asking schools to provide information on curriculum contents addressing the consequences and management of COI and (b) noting curricular teaching activities identified via the web search. Evidence of curricular teaching was

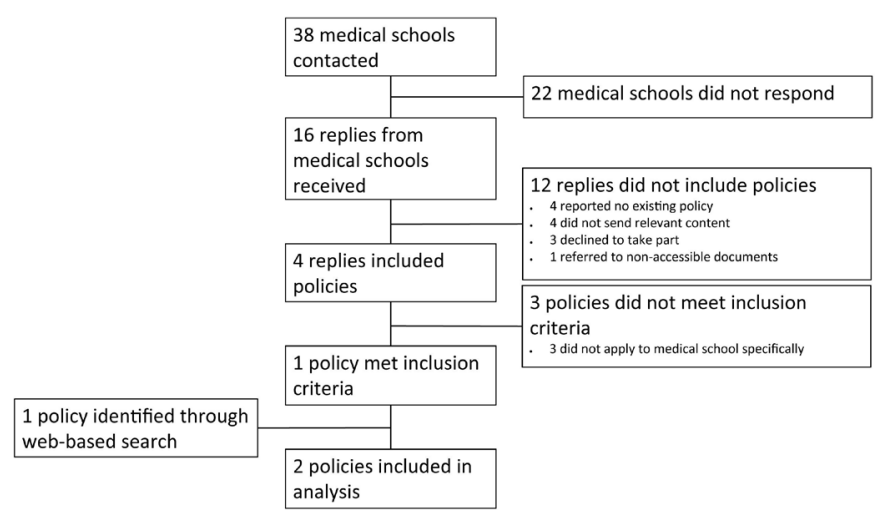

Figure 1 Flowchart of included conflict of interest policies.

graded as outlined in the codebook, page 15 (see online supplemental file 2).

Subsequently, we graded the results for each category through our scoring system from 0 to 2 . Generally, ' 0 ' means no policy or a permissive policy, ' 1 ' a moderate policy and '2' a restrictive policy. Medical schools with no identified policy or curriculum in both survey and websearch were also rated with a score of 0 . The translated codebook in English, outlining the decision pathway for each category is available as online supplemental file 2 . Three reviewers (LH, TW, ST) independently undertook the scoring of the medical schools' policies. All authors then reviewed the scoring. Any disagreement was resolved through discussion and majority vote. We then summed up the scores of all individual categories for each medical school to create a global score, with a range of $0-26$ points. No weighting of single categories was performed.

\section{RESULTS \\ Web-based search}

The web-based search on medical school's websites was conducted to identify publicly available COI policies and evidence for curricular teaching activities addressing COI at German medical schools. The search yielded relevant results for one of the 38 medical schools: an anti-corruption brochure and a third-party funds statute from Charité-Universitätsmedizin Berlin (figure 1). Additional articles and publications were identified but excluded from analysis because they either did not relate to predefined criteria or did not specifically apply to the entire medical school. Our web-based search strategy revealed no information on relevant compulsory curricular teaching activities addressing COI that could receive a score (cf. Codebook page 15, online supplemental file 2). Only one non-compulsory elective course at FriedrichSchiller-Universität Jena was identified.

\section{Contacting medical schools}

German medical schools were contacted to provide validated insight into existing COI policies. The total response rate was $42.1 \%$ (16 of 38). Twelve of the responding medical schools did not send policies. Four medical schools $(10.5 \%)$ included policies dealing with COI, of 
Table 1 Overview of the answers received from medical schools

\begin{tabular}{|c|c|c|}
\hline Medical school & $\begin{array}{l}\text { Response contained a policy } \\
\text { meeting inclusion criteria }\end{array}$ & $\begin{array}{l}\text { If applicable: response included a } \\
\text { statement on curricular teaching } \\
\text { activities }\end{array}$ \\
\hline $\begin{array}{l}\text { Medizinische Fakultät } \\
\text { Carl Gustav Carus } \\
\text { der Technischen Universität Dresden }\end{array}$ & Yes & NA \\
\hline Universitätsmedizin Greifswald & No & NA \\
\hline Universität des Saarlandes (Homburg) & No & NA \\
\hline Friedrich-Schiller-Universität Jena & No & NA \\
\hline Ludwig-Maximilians-Universität München & No & NA \\
\hline Westfälischen Wilhelms-Universität Münster & No & NA \\
\hline Justus-Liebig-Universität Gießen & No & NA \\
\hline Albert-Ludwigs-Universität Freiburg & No & No explicit curricular teaching on COI \\
\hline Georg-August-Universität Göttingen & No & No explicit curricular teaching on COI \\
\hline Christian-Albrechts-Universität zu Kiel & No & No explicit curricular teaching on COI \\
\hline Julius-Maximilians-Universität Würzburg & No & No explicit curricular teaching on COI \\
\hline Universität Augsburg & No & NA \\
\hline
\end{tabular}

The schools not mentioned in the table did not reply to any of our three emails sent. Those are: Universität Augsburg, RWTH Aachen, Charité-Universitätsmedizin Berlin, Ruhr-Universität Bochum, Rheinischen Friedrich-Wilhelms-Universität Bonn, Universität Duisburg-Essen, Heinrich-Heine-Universität Düsseldorf, Martin-Luther-Universität Halle-Wittenberg, Medizinische Hochschule Hannover, Ruprecht-KarlsUniversität Heidelberg, Universität zu Köln, Universität Leipzig, Universität zu Lübeck, Otto-von-Guericke-Universität Magdeburg, JohannesGutenberg-Universität Mainz, Medizinische Fakultät Mannheim der Ruprecht-Karls-Universität Heidelberg, Philipps-Universität Marburg, Technischen Universität München, Carl von Ossietzky Universität Oldenburg, Universität Regensburg, Universitätsmedizin Rostock, Eberhard Karls Universität Tübingen.

which three (an anti-corruption directive and a monetary benefit acceptance policy from the Ludwig-MaximilianUniversität München, a code of practice as well as an anti-corruption directive from the Julius-MaximiliansUniversität Würzburg, a compliance brochure, gifts and benefits acceptance policy, and a third-party funds statute from the Friedrich-Schiller-Universität Jena) exclusively applied to university medical centres, not to the respective medical schools, and were therefore excluded from further analysis. One policy met inclusion criteria and comprised an anti-corruption directive issued by the medical school and university medical centre of the Technische Universität Dresden (figure 1).

See table 1 for an overview of the answers received from the medical schools.

Of the total of 16 replies, 5 medical schools $(13.2 \%)$ (Universität des Saarlandes, Albert-Ludwigs-Universität Freiburg, Georg-August-Universität Göttingen, ChristianAlbrechts-Universität zu Kiel, Universität Witten/ Herdecke) responded not having COI policies or that COI were not part of the curriculum. The Universität des Saarlandes stated that there was no separate policy for the medical school, while the Albert-Ludwigs-Universität
Freiburg declared not having a COI policy within the medical curriculum, as well as no explicit lectures on COI. In addition, the Christian-Albrechts-Universität zu Kiel reported no existing COI policy within their medical school, neither was the topic taught in the medical curriculum. The reply from the Georg-August-Universität Göttingen stated that basic knowledge about pharmacoeconomics was taught, however, not mentioning corruption and transparency within the medical system. As stated by the Universität Witten/Herdecke, COI management lies with the contracted teaching hospitals. The Friedrich-Alexander-Universität Erlangen-Nürnberg replied that several policies apply within their university; however, no COI policy relevant to this study, issued by the medical school itself is externally available. The Universität Greifswald and the Medizinische Fakultät der Universität Hamburg initially asked for more time to reply, yet did not send material by the end of the data collection period. The Universität Augsburg was still in the process of setting up a medical curriculum, welcoming medical students starting in 2019 and was hence not able to report on COI policies or teaching activities. No further response as to whether a general COI policy existed was received. 


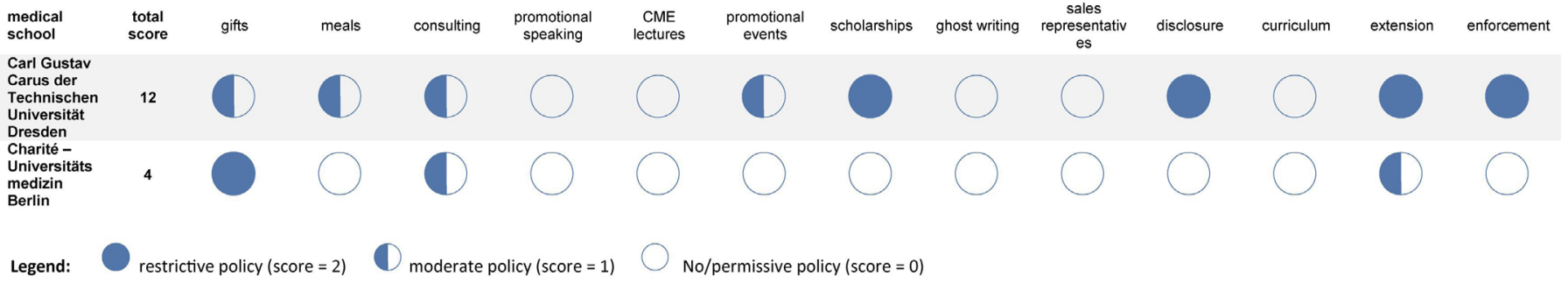

Figure 2 Overview of strength of the two COI policies included. empty circle=permissive/no policy (score=0), half-circle: moderate policy (score=1), full circle=restrictive policy (score=2). Criteria were prespecified in the codebook (see online supplemental file 2). Categories were assessed separately and without weighing.

The Westfälische-Wilhelms-Universität Münster and the Goethe-Universität Frankfurt reported no capacities to take part in our study, while the Justus-Liebig-Universität Gießen actively decided against participating. The Universität Ulm addressed neither COI policies nor curriculum contents in their reply. The remaining medical schools did not respond to any request during the data acquisition period.

\section{Analysis of COI policies}

The two included policies were assessed according to a predefined scoring system as set out in our codebook (see online supplemental file 2). Results of each analysis are listed in figure 2.

With 12 out of 26 points, the Technische Universität Dresden achieved the highest score. Charité Universitätsmedizin Berlin scored four points in total. All other medical schools did not supply a valid COI policy and had no retrievable information on COI policies on their websites according to inclusion criteria (figure 1).

We did not acquire any information about obligatory teaching activities on COI through web-based search or the deans' survey. However, through personal contacts and seeking advice from experts, we received information on courses that cover COI at three medical schools (7.9\%): Charité Universitätsmedizin Berlin, Universität Mainz and Universität Leipzig. These teaching activities are either lectures in which COI is discussed (Universität Leipzig, Universität Mainz, Charité Universitätsmedizin Berlin) or elective courses that students can choose within their curriculum (Charité Universitätsmedizin Berlin, Universität Mainz).

\section{DISCUSSION}

\section{Statement of principal findings}

In this cross-sectional study and survey of German medical schools, we found that only two German medical schools $(5.3 \%)$ have policies relating to COI in place. Moreover, none of these policies sufficiently covered the broad spectrum of evaluated categories with relevance to COI, nor did they focus explicitly on the context of medical education. No medical school reported curricular teaching on COI. The maximum score achieved was 12 of $26.36(94.7 \%)$ schools were rated with a score of 0. Those also included non-responders to the survey without discoverable policies in the web-search (22 schools, $61 \%$ ). These results indicate little effort by German medical schools to address the issue of COI in medical education.

\section{Strengths and limitations of the study}

In total, 16 out of 38 medical schools responded to our letter and emails, and therefore, COI teaching activities and policies by non-responding medical schools may have been missed. To address this issue, we conducted a systematic web-search, which in general supported the results of the survey. The policy identified for Charité Universitätsmedizin Berlin was evaluated without a response from the dean's office to validate the document retrieved online. The web-search was performed with few predefined search terms using integrated search engines on the websites of medical schools, thus limiting potentially retrievable documents. Consequently, the results of this study might underestimate the number of COI policies and teaching activities that are publicly available. However, scarce results among the 16 medicals schools participating in the survey as well as from the web-search indicate that too few German medical schools adopted policies on COI and educate their students about COI.

Medical schools do not exist in a vacuum, and further COI policies may exist at a university-wide level or at university medical centres. We argue that the consequences of COI in medicine potentially harm patient health and are, therefore, even more critical compared with COI that might occur in other fields. Thus, medical schools require more restrictive COI policies than other departments within a university. Teaching physicians are predominantly also employed by a university medical centre which might issue COI policies not specifically applying to their affiliated medical school. However, these policies are aimed at COI of physicians working in patient care and lack specific regulations that apply to the teaching environment of medical students. It predominantly lies within the capacity of teaching faculty at medical schools to introduce core knowledge on COI in the classroom. In this study, teaching on COI contributed to the overall score as one of 13 categories. This might underrepresent the importance of teaching activities within the efforts of medical schools to address COI during medical studies. 
Strengths and limitations in relation to other studies, discussing important differences in results

Comparable studies were conducted in USA, Canada, Australia and France, allowing for an international comparison of our results. ${ }^{25-27} 30$ In general, North American medical schools tackle the issue of COI in medical education more proactively. In Canada 16 of 17 medical schools had some form of COI policy in place in $2013^{26}$ and in 2014, 136/160 US medical schools reported an existing policy on COI. ${ }^{25}$ The Australian study found that 7 medical schools out of 20 had a COI policy. ${ }^{30}$ The French study exposed similar results as our own data. They found no formal COI policy at any of the 37 French medical schools and only scattered COI teaching activities. Their response rate of $8.1 \%$ may be indicative of the low interest in the topic by medical schools at this time. The publication of these results led to increased media attention, ${ }^{31}$ and ultimately, the French deans' conference adopted a nation-wide COI policy. ${ }^{32}$

The best performing policy in our study was an anticorruption directive issued by the Technische Universität Dresden that included four restrictive and four moderate elements related to different scoring categories. Yet we were unable to retrieve this policy from the medical school's website during the performed web-search. Prior studies excluded non-public policies from analysis, since an inaccessible, not widely circulated policy is unlikely to have a relevant impact and may go unrecognised by academic staff. ${ }^{26}{ }^{30}$ In an earlier study, two German medical schools were reported to have a policy on COI. ${ }^{20}$ Our research could only verify one of those COI policy equivalents at TU Dresden. RWTH Aachen reported a policy in 2014 but did not reply to our study, nor was a policy identified on the school's website. Despite six medical schools committed to the development of a COI policy in $2014,{ }^{20}$ our results indicate that no policy has been published since. Furthermore, we did not receive any information about teaching on COI through the deans' survey. This is in contrast to the survey by Lieb and Koch. ${ }^{20}$ In their study, deans from seven medical schools reported COI teaching activities (Universität Bonn, Universität Erlangen-Nürnberg, Universität des Saarlandes (Homburg), Universität Gießen, Universität Göttingen, Universität Frankfurt, Universität Köln). From these medical schools, only the dean's office of Universität Göttingen commented on COI teaching and declared that their curriculum included basic education on pharmacoeconomics but did not explicitly cover COI related aspects like transparency or corruption.

\section{Implications for medical schools and policymakers}

Education and policies on COI have been suggested to sensitise medical students in favour of the independence of medical education from undue industry influence. ${ }^{4}$ 22-24 Medical students themselves increasingly demand stronger COI regulations, disclosure of teaching faculty's COI and courses on COI. The German Medical Students' Association (bvmd e.V.) adopted a position paper on the independence of education in $2013 .{ }^{33}$ In May 2019 the European Medical Students Association passed a policy titled 'Conflicts of Interest in Medical Education Settings ${ }^{\text {'34 }}$ and the International Medical Students' Association followed in August 2019 with a policy called 'Integrity and transparency in medical education'. ${ }^{35}$ These actions are indicative of broader student interest in policy change.

We found COI teaching activity at German medical schools, if existent, to be an initiative by singular faculty members rather than a structured component of the curriculum. Those mostly encompassed elective courses or singular lectures that are not available to all students and hence received no score. The scarce efforts to include COI in teaching are all the more surprising, since the German National Competence-Based Learning Objectives for Undergraduate Medical Education include COI (without specifically naming them) in chapter 11.1.1.2. ${ }^{36}$ Moreover, the "Institut für medizinische und pharmazeutische Prüfungsfragen" (IMPP, institute for medical and pharmaceutical examination questions) that develops national exams for medical students in Germany introduced an item directly referring to $\mathrm{COI}$ in its latest edition published in November 2019. Recently, a randomised controlled trial showed that a structured and integrated curriculum on COI and risk communication leads to a large and sustainable increase in risk communication performance among German medical students. ${ }^{37}$ Taking the mounting evidence, broad student engagement and changing requirements into consideration, German medical schools are under pressure to adopt structured COI curricula and policies that are mandatory to all students and form part of a core curriculum.

\section{Unanswered questions and future research}

In the US, the regular AMSA scorecard assessed COI policies at US medical schools until 2016 and contributed to a constant improvement in policies since its initiation in $2007 .^{25}$ Regular evaluation of the development of policies and curricula addressing COI might also be useful in Germany to incentivise and monitor progress towards better COI education at medical schools.

Policy development is a dynamic process and some schools signalled willingness to introduce teaching activities and considered COI policies after we contacted them. This, however, was also the case in previous studies. ${ }^{20}$ Yet, our work indicates that little action was taken since then. Future research should further assess the impact of stringent policies during medical training on prescribing behaviour, and ultimately evaluate other patient relevant outcomes.

\section{CONCLUSION}

In contrast to other parts of the world, such as North America, German medical schools barely regulate students' contact with pharmaceutical companies or teach about the impacts of COI. Several organisations ${ }^{38} 39$ 
and increasingly students themselves are demanding a cultural change in the medical profession starting with independent, unbiased medical education. ${ }^{33-35}$ COI policies at medical schools have been shown to positively impact prescribing and practise. ${ }^{22-24}$ Medical schools in Germany have a key responsibility to protect students from undue influence and enable them to critically appraise information to achieve the best possible patient care. Although national learning objectives include teaching on COI, German medical schools do too little and have a long way to go.

\section{Twitter Peter Grabitz @PeterRolandG}

Acknowledgements The authors wish to thank all participating medical schools for contributing to this study as well as the German Medical Students' Association (bvmd e.V)., Christiane Fischer (MEZIS e.V.), Cora Koch, Marlene Stoll, Paul Scheffer, Reshma Ramachandran and Barbara Mintzes for their valuable support of this project. We also acknowledge the support from the German Research Foundation (DFG) and the Open Access Publication Funds of Charité - Universitätsmedizin Berlin.

Contributors PG, ZF, LH, LS, MS, SKT, TW and DK designed the study. PG, ZF, SG, LH, LS, MS, SKT, TW conducted the survey. MS and LS performed the web-based search. PG, LH, ST, TW evaluated obtained results. PG and LH wrote the manuscript. All authors reviewed the manuscript.

Funding The authors have not declared a specific grant for this research from any funding agency in the public, commercial or not-for-profit sectors.

Competing interests All authors have completed the Unified Competing Interest form (available on request from the corresponding author) and declare: no financial support from any organisation for the submitted work; SG previously consulted for Universities Allied for Essential Medicines (UAEM) Europe e.V.; all other authors declare no financial relationships with any organisations that might have an interest in the submitted work in the previous 3 years and no other relationships or activities that could appear to have influenced the submitted work.

\section{Patient consent for publication Not required.}

Ethics approval After formal exchange with a member of the German Ethics Council about the nature of this study, which only involves policies at an institutional level rather than patient data or other personal information, it was deemed unnecessary to ask for formal approval from an ethics committee.

Provenance and peer review Not commissioned; externally peer reviewed. Data availability statement Data are available upon reasonable request.

Open access This is an open access article distributed in accordance with the Creative Commons Attribution Non Commercial (CC BY-NC 4.0) license, which permits others to distribute, remix, adapt, build upon this work non-commercially, and license their derivative works on different terms, provided the original work is properly cited, appropriate credit is given, any changes made indicated, and the use is non-commercial. See: http://creativecommons.org/licenses/by-nc/4.0/.

ORCID iD

Peter Grabitz http://orcid.org/0000-0001-5658-2482

\section{REFERENCES}

1 Institute of Medicine (US) Committee on Conflict of Interest in Medical Research, Education, and Practice. Conflict of interest in medical research, education, and practice. Washington, DC: National Academies Press, 2009. http://www.ncbi.nlm.nih.gov/books/ NBK22942/

2 Goupil B, Balusson F, Naudet F, et al. Association between gifts from pharmaceutical companies to French general practitioners and their drug prescribing patterns in 2016: retrospective study using the French transparency in healthcare and national health data system databases. BMJ 2019;367:I6015.

3 Austad KE, Avorn J, Kesselheim AS. Medical students' exposure to and attitudes about the pharmaceutical industry: a systematic review. PLoS Med 2011;8:e1001037.
4 Wilkes MS, Hoffman JR. An innovative approach to educating medical students about pharmaceutical promotion. Acad Med 2001;76:1271-7.

5 Lea D, Spigset O, Slørdal L. Norwegian medical students' attitudes towards the pharmaceutical industry. Eur J Clin Pharmacol 2010;66:727-33.

6 Sierles FS, Brodkey AC, Cleary LM, et al. Medical students' exposure to and attitudes about drug company interactions: a national survey. JAMA 2005;294:1034.

7 Lieb K, Koch C. Medical students' attitudes to and contact with the pharmaceutical industry. Dtsch Arztebl Int 2013;110:584-90.

8 Etain B, Guittet L, Weiss N, et al. Attitudes of medical students towards conflict of interest: a national survey in France. PLoS One 2014;9:e92858.

9 Beyhun NE, Kolayli CC, Can G, et al. Turkish final year medical students' exposure to and attitudes concerning drug company interactions: a perspective from a minimally regulated environment for medical students. PLoS One 2016;11:e0168094.

10 Filippiadou M, Kouvelas D, Garyfallos G, et al. Exposure to the drug company marketing in Greece: interactions and attitudes in a non-regulated environment for medical students. Ann Med Surg 2017;19:23-8.

11 Saito S, Maeno T, Miyata Y, et al. Medical students' attitudes toward interactions with the pharmaceutical industry: a national survey in Japan. BMC Med Educ 2018;18:286.

12 Bellin M, McCarthy S, Drevlow L, et al. Medical students' exposure to pharmaceutical industry marketing: a survey at one U.S. medical school. Acad Med 2004;79:1041-5.

13 Austad KE, Avorn J, Franklin JM, et al. Changing interactions between physician trainees and the pharmaceutical industry: a national survey. J Gen Intern Med 2013;28:1064-71.

14 Hafferty FW. Beyond curriculum reform: confronting medicine's hidden curriculum. Acad Med 1998;73:403-7.

15 Ärzteblatt D. Ein physician payments sunshine act für Deutschland? Eine Stellungnahme zu Vor- und Nachteilen. Deutsches Ärzteblatt 2019;116:A390-2.

16 Grill M, Wehrmeyer S. Pharmakonzerne haben 562 Millionen Euro an Ärzte gezahlt, 2017. Available: https://correctiv.org/aktuelles/eurosfuer-aerzte/2017/06/21/pharmakonzerne-haben-562-millionen-euroan-aerzte-gezahlt/ [Accessed 15 Oct 2019].

17 Cho MK, Shohara R, Schissel A, et al. Policies on faculty conflicts of interest at US universities. JAMA 2000;284:2203-8.

18 Ehringhaus SH, Weissman JS, Sears JL, et al. Responses of medical schools to institutional conflicts of interest. JAMA 2008;299:665-71.

19 Jahnke K, Kremer MS, Schmidt CO, et al. German medical students' exposure and attitudes toward pharmaceutical promotion: a crosssectional survey. GMS Z Med Ausbild 2014;31:Doc32.

20 Lieb K, Koch C. Conflicts of interest in medical school: missing policies and high need for student information at most German universities. GMS Z Med Ausbild 2014;31:Doc10.

21 Kao AC, Braddock C, Clay M, et al. Effect of educational interventions and medical school policies on medical students' attitudes toward pharmaceutical marketing practices: a multiinstitutional study. Acad Med 2011;86:1454-62.

22 Larkin I, Ang D, Avorn J, et al. Restrictions on pharmaceutical detailing reduced off-label prescribing of antidepressants and antipsychotics in children. Health Aff 2014;33:1014-23.

23 King M, Essick C, Bearman P, et al. Medical school gift restriction policies and physician prescribing of newly marketed psychotropic medications: difference-in-differences analysis. BMJ 2013;346:f264.

24 Epstein AJ, Busch SH, Busch AB, et al. Does exposure to conflict of interest policies in psychiatry residency affect antidepressant prescribing? Med Care 2013;51:199-203.

25 Carlat DJ, Fagrelius T, Ramachandran R, et al. The updated AMSA scorecard of conflict-of-interest policies: a survey of U.S. medical schools. BMC Med Educ 2016;16:202.

26 Shnier A, Lexchin J, Mintzes B, et al. Too few, too weak: conflict of interest policies at Canadian medical schools. PLoS One 2013;8:e68633

27 Scheffer P, Guy-Coichard C, Outh-Gauer D, et al. Conflict of interest policies at French medical schools: starting from the bottom. PLoS One 2017;12:e0168258.

28 MFT Medizinischer Fakultätentag Der Bundesrepublik Deutschland E. V. Mitglieder Medizinischer Fakultätentag. Available: https:// medizinische-fakultaeten.de/verband/mitglieder/ [Accessed $26 \mathrm{Sep}$ 2018].

29 Mintzes B, Mangin D H. Understanding and responding to pharmaceutical promotion: a practical guide, 2010.

30 Mason PR, Tattersall MHN. Conflicts of interest: a review of institutional policy in Australian medical schools. Med J Aust 2011:194:121-5. 
31 Conflits d'intérêts avec les laboratoires pharmaceutiques : les facs de médecine épinglées. Le Monde.fr, 2017. Available: https://www. lemonde.fr/sante/article/2017/01/10/prevention-des-conflits-dinterets-les-facs-de-medecine-epinglees_5060033_1651302.html [Accessed 22 Sep 2019].

32 Randé J-LD, Taddei-Gross C. Ethical and deontological charter of the ceans' conferences of medicine and odontology schools, 2017. Available: https://formindep.fr/wp-content/uploads/2017/11/deancharter-english.pdf [Accessed 10 Sep 2019].

33 Bundesvertretung der Medizinstudierenden in Deutschland. BVMD Positionspapier Beeinflussung Der Freiheit von Lehre, 2013. Available: https://www.bvmd.de/fileadmin/redaktion/ Positionspapiere/2013-11-02_Beeinflussung_der_Freiheit_von_Lehre. pdf [Accessed 22 Sep 2019].

34 Mosch LK, Balciunas J, de Jong R, et al. Conflicts of interest in medical education settings. Available: https://emsa-europe.eu/wpcontent/uploads/2019/05/Policy-Statement-Conflicts-of-Interest-inMedical-Education-Settings-1.pdf
35 International Federation of Medical Students Associations. IFMSA policy document - Integrity and transparency in medical education, 2019. Available: https://ifmsa.org/wp-content/uploads/2019/ 09/AM19-Integrity-and-transparency-in-medical-education.pdf [Accessed 22 Sep 2019].

36 Kapitel 11 Die Ärztin und der Arzt als professionell Handelnde/-r - NKLM. Available: http://www.nklm.de/kataloge/nklm/lernziel/ uebersicht/kapitel/7 [Accessed 22 Sep 2019].

37 Koch C, Dreimüller N, Weißkircher J, et al. Teaching conflicts of interest and shared decision-making to improve risk communication: a randomized controlled trial. J Gen Intern Med 2020;35:473-80.

38 Korn D, Carlat D. Conflicts of interest in medical education: recommendations from the Pew Task force on medical conflicts of interest. JAMA 2013;310:2397-8.

39 Korzilius H. Das Gespräch mit Dr. med. Christiane Fischer, Geschäftsführerin von 'Mezis - Initiative unbestechlicher Ärztinnen und Ärzte' -Eine andere Medizin ist möglich. Dtsch Arztebl International 2016;113:A-918. 